Supporting Information

\title{
Poly(propylene vanillate): a sustainable lignin-based semicrystalline engineering polyester
}

\author{
Eleftheria Xanthopoulou ${ }^{\dagger, t}$, Zoi Terzopoulou ${ }^{\dagger,}$, , Alexandra Zamboulis ${ }^{\dagger}$, Lazaros \\ Papadopoulos ${ }^{\prime}$, Konstantinos Tsongas ${ }^{\S}$, Dimitrios Tzetzis ${ }^{\S}$, George Z. Papageorgiou ${ }^{*}, \ldots, l$, \\ Dimitrios N. Bikiaris ${ }^{*},+$ \\ $\dagger$ Laboratory of Polymer Chemistry and Technology, Department of Chemistry, Aristotle \\ University of Thessaloniki, GR-54124 Thessaloniki, Greece
}

$\$$ Department of Chemistry, University of Ioannina, P.O. Box 1186, GR-45110 Ioannina, Greece

$\S$ Digital Manufacturing and Materials Characterization Laboratory, School of Science and Technology, International Hellenic University, 14km Thessaloniki, 57001 N. Moudania, Greece "Institute of Materials Science and Computing, University Research Center of Ioannina (URCI), Ioannina, 45110, Greece

*Corresponding authors: gzpap@uoi.gr;

dbic@,chem.auth.gr

It contains 9 pages with 10 Figures, 4 Tables and a description of data. 


\section{NMR analysis}

4-(3-hydroxypropoxy)-3-methoxybenzoic acid

${ }^{1} \mathrm{H}$ NMR (500 MHz, DMSO-d 6 , $): 12.64(\mathrm{~s}, 1 \mathrm{H}), 7.55(\mathrm{dd}, J=8.4,1.7 \mathrm{~Hz}, 1 \mathrm{H}), 7.44(\mathrm{~d}, J=1.7$ $\mathrm{Hz}, 1 \mathrm{H}), 7.03(\mathrm{~d}, J=8.4 \mathrm{~Hz}, 1 \mathrm{H}), 4.56(\mathrm{~s}, 1 \mathrm{H}), 4.09(\mathrm{t}, J=6.3 \mathrm{~Hz}, 2 \mathrm{H}), 3.80(\mathrm{~s}, 3 \mathrm{H}), 3.56(\mathrm{~m}, 2 \mathrm{H})$, 1.88 (quint, $J=6.2 \mathrm{~Hz}, 2 \mathrm{H}) .{ }^{13} \mathrm{C} \mathrm{NMR}\left(126 \mathrm{MHz}, \mathrm{DMSO}_{-}, \delta\right): 167.2,152.1,148.4,123.3,122.8$, 112.1, 111.8, 65.4, 57.3, 55.5, 32.0.

Poly(propylene vanillate)

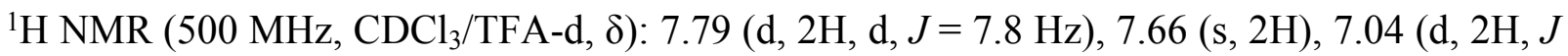
$=8.5 \mathrm{~Hz}), 4.62(\mathrm{t}, 2 \mathrm{H}, J=5.6 \mathrm{~Hz}), 4.35(\mathrm{~m}, 2 \mathrm{H}), 4.00(\mathrm{~s}, 3 \mathrm{H}), 2.41(\mathrm{~m}, 2 \mathrm{H}) .{ }^{13} \mathrm{C} \mathrm{NMR}(126 \mathrm{MHz}$, $\mathrm{CDCl}_{3}$ /TFA-d, $\left.\delta\right): 169.7,153.1,148.1,125.8,122.06,113.6,112.0,65.9,63.5,56.4,28.2$.

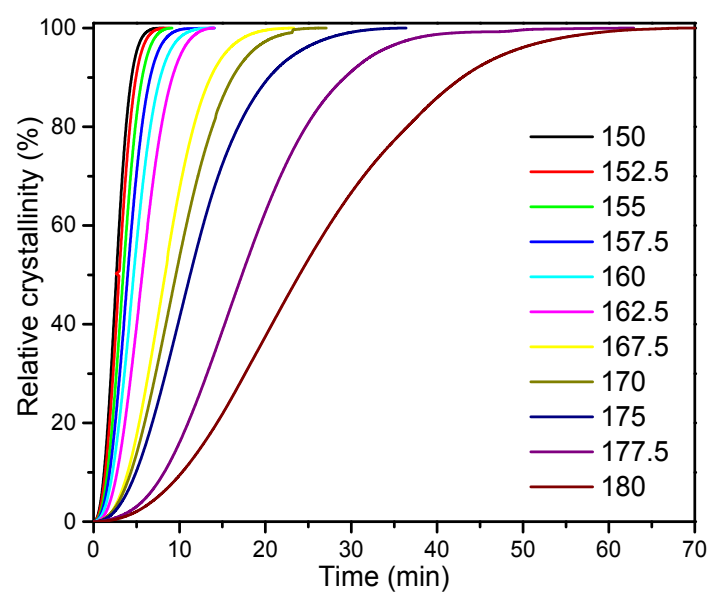

Figure S1. Evolution of the relative degree of crystallinity of PPV with time during isothermal crystallization from the melt at different temperatures. 


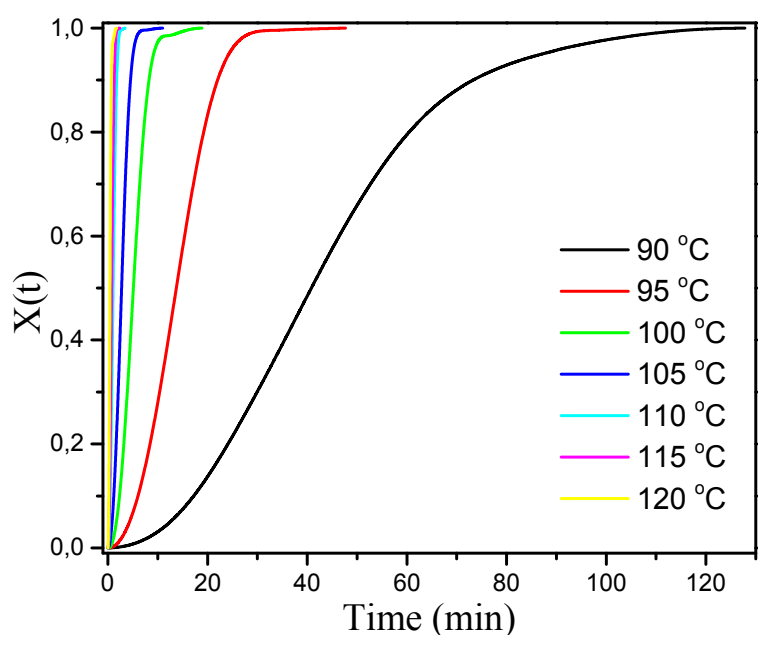

Figure S2. Evolution of the relative degree of crystallinity of PPV with time during isothermal cold crystallization at different temperatures. 

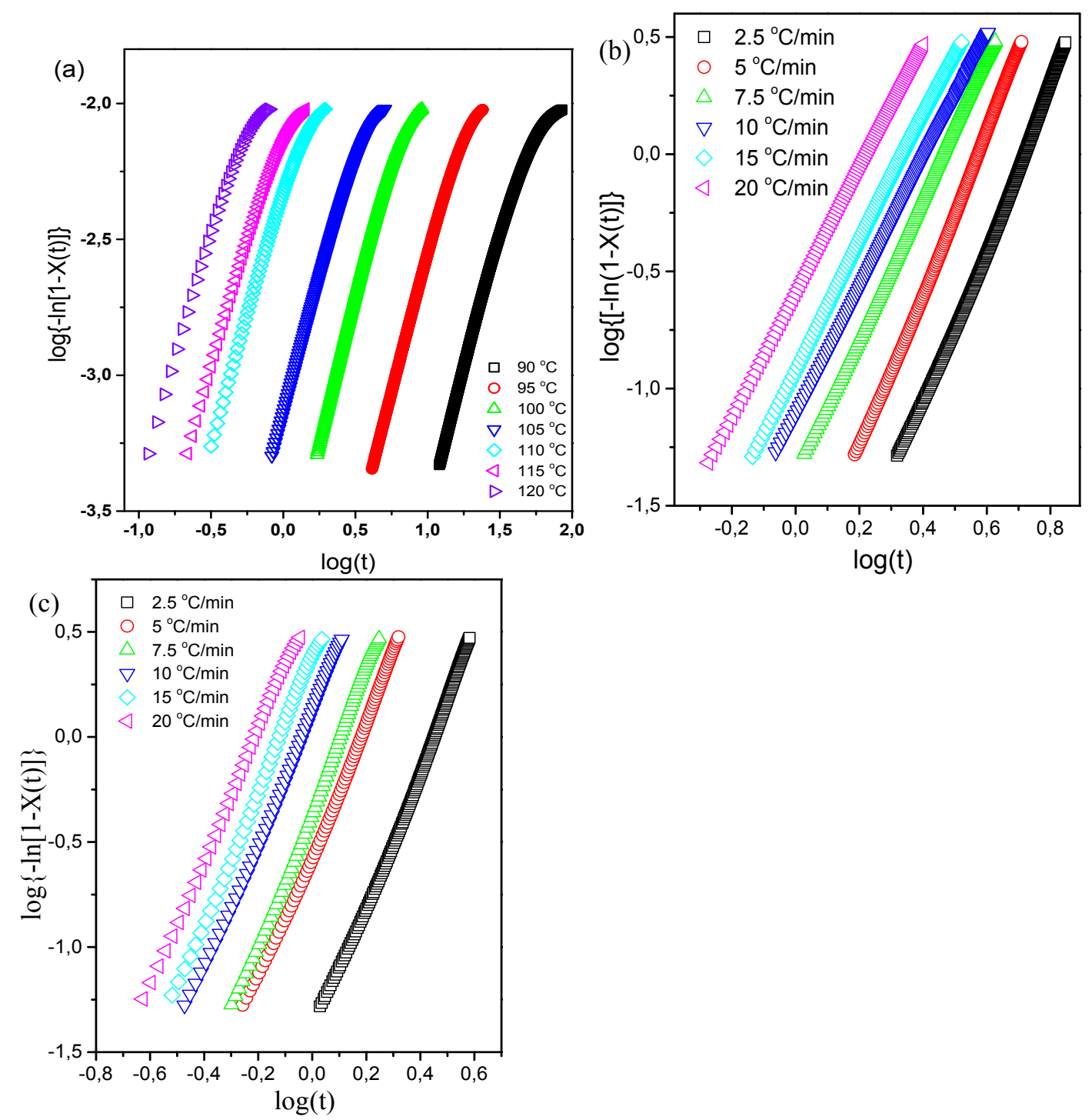

Figure S3. Avrami plots for the (a) isothermal cold crystallization (b) the non-isothermal crystallization from the melt and (c) the non-isothermal cold crystallization of PPV. 


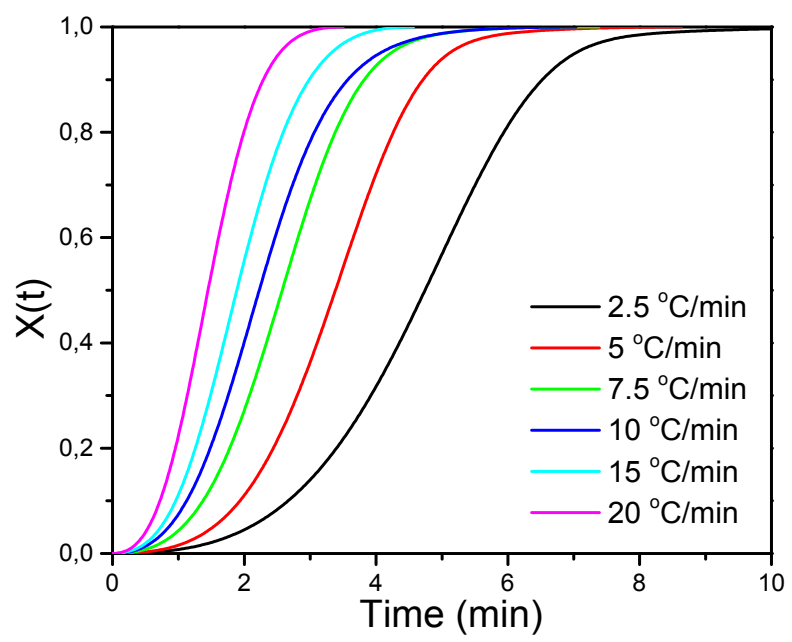

Figure S4. Evolution of relative degree of crystallinity with time at different cooling rates in melt non-isothermal crystallization.
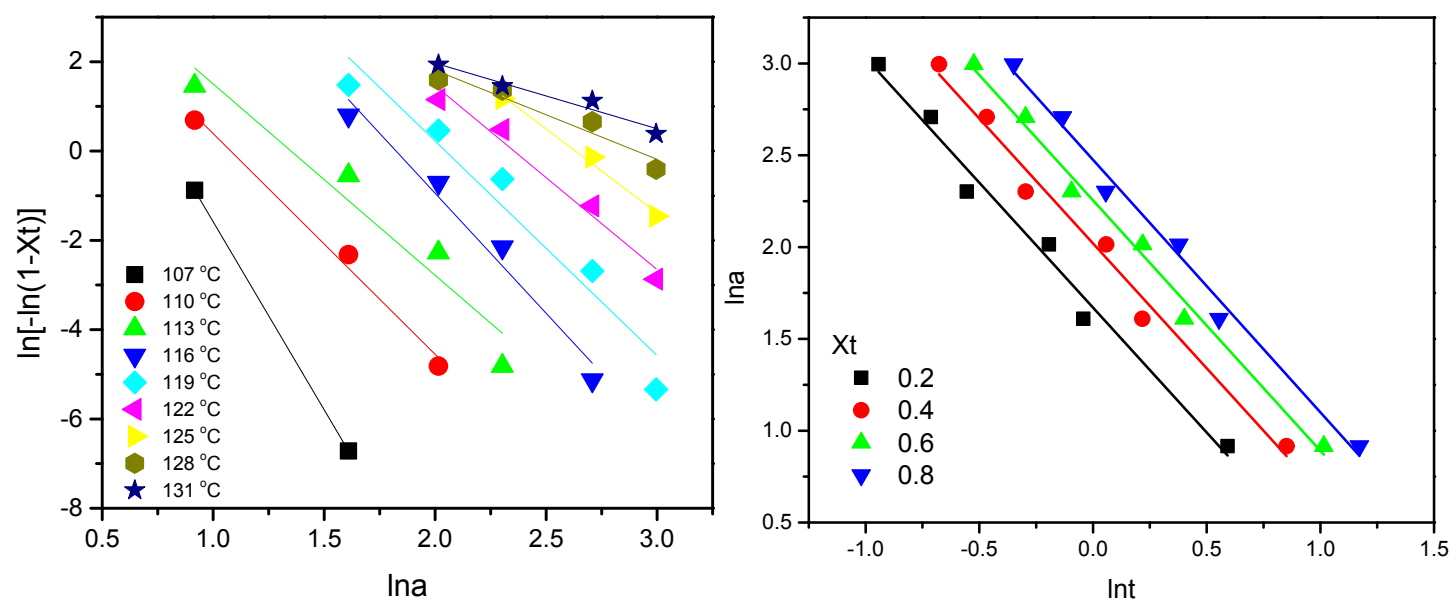

Figure S5. (a) Ozawa and (b) Mo plots for the non-isothermal cold-crystallization of PPV.

Table S1. Ozawa parameters of the non-isothermal cold-crystallization of PPV.

\begin{tabular}{|l|l|l|l|l|l|l|l|l|l|}
\hline $\begin{array}{l}\text { Temperatur } \\
\mathrm{e}\left({ }^{\circ} \mathrm{C}\right)\end{array}$ & 107 & 110 & 113 & 116 & 119 & 122 & 125 & 128 & 131 \\
\hline $\mathrm{m}$ & $\begin{array}{l}8.4 \\
2\end{array}$ & 4.94 & 4.28 & 5.37 & 4.80 & 4.12 & 3.76 & 2.00 & 1.47 \\
\hline
\end{tabular}




\begin{tabular}{|l|l|l|l|l|l|l|l|l|l|}
\hline $\ln \mathrm{K}(\mathrm{T})$ & $\begin{array}{l}6.8 \\
4\end{array}$ & 5.33 & 5.79 & 9.80 & 9.83 & 9.70 & 9.91 & 5.80 & 4.91 \\
\hline $\mathrm{R}^{2}$ & - & $\begin{array}{l}0.9817 \\
1\end{array}$ & $\begin{array}{l}0.9049 \\
1\end{array}$ & $\begin{array}{l}0.9573 \\
2\end{array}$ & $\begin{array}{l}0.923 \\
6\end{array}$ & $\begin{array}{l}0.9637 \\
3\end{array}$ & $\begin{array}{l}0.980 \\
2\end{array}$ & $\begin{array}{l}0.8881 \\
1\end{array}$ & $\begin{array}{l}0.9311 \\
6\end{array}$ \\
\hline
\end{tabular}

Table S2. Results of the Mo analysis of the non-isothermal cold-crystallization of PPV.

\begin{tabular}{|l|l|l|l|l|}
\hline $\begin{array}{l}\text { Relative } \\
\text { crystallinity X/\% }\end{array}$ & 20 & 40 & 60 & 80 \\
\hline $\mathrm{b}$ & 1.36 & 1.36 & 1.36 & 1.38 \\
\hline $\mathrm{F}(\mathrm{T})\left(\mathrm{K} \cdot \mathrm{min}^{\mathrm{b}-1}\right)$ & 1.67046 & 2.02011 & 2.25481 & 2.47533 \\
\hline $\mathrm{R}^{2}$ & 0.98037 & 0.98167 & 0.98924 & 0.98688 \\
\hline
\end{tabular}

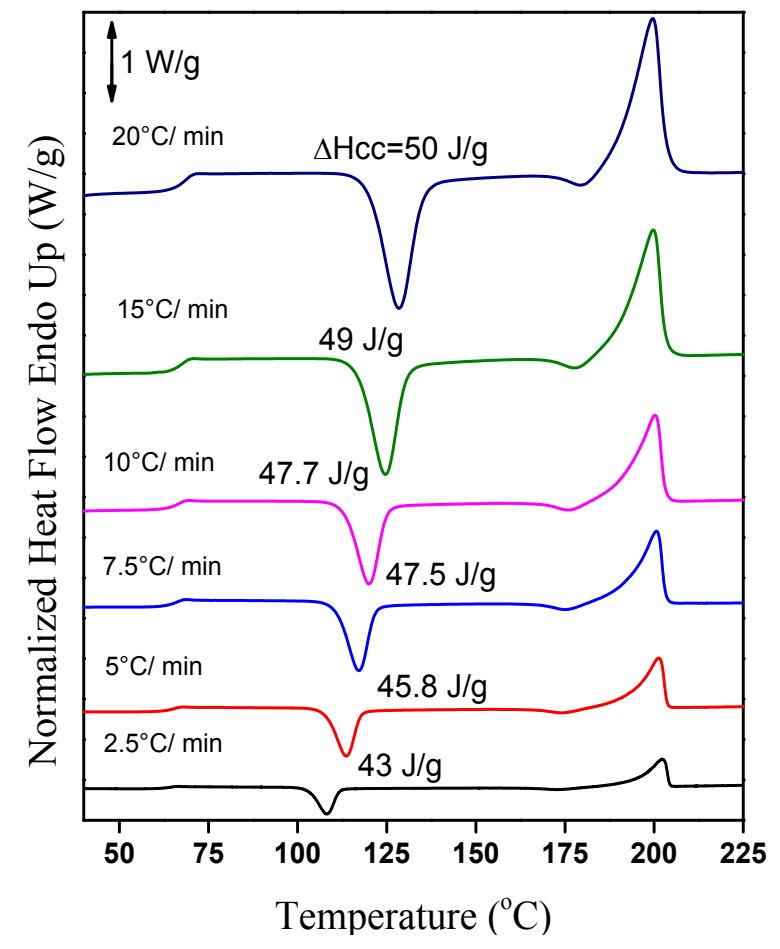

Figure S6. Non-isothermal cold crystallization DSC scans of PPV. 


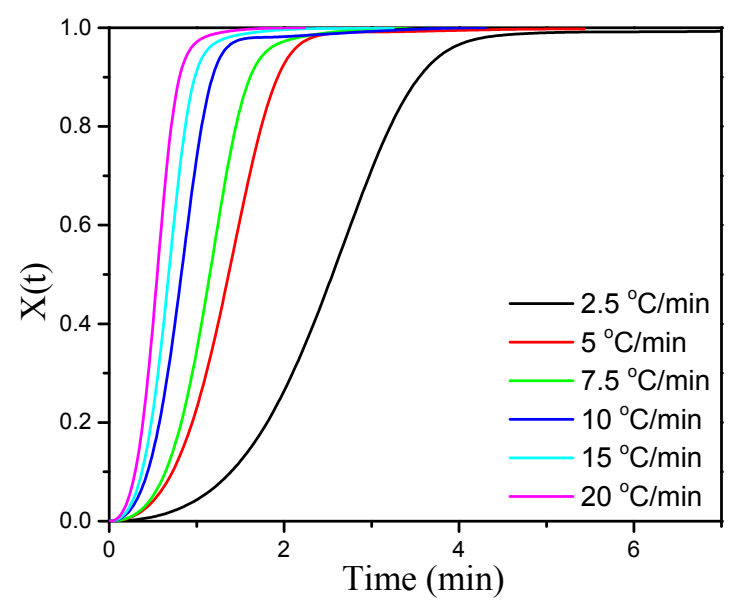

Figure S7. Evolution of relative degree of crystallinity with time at different heating rates in nonisothermal cold-crystallization.

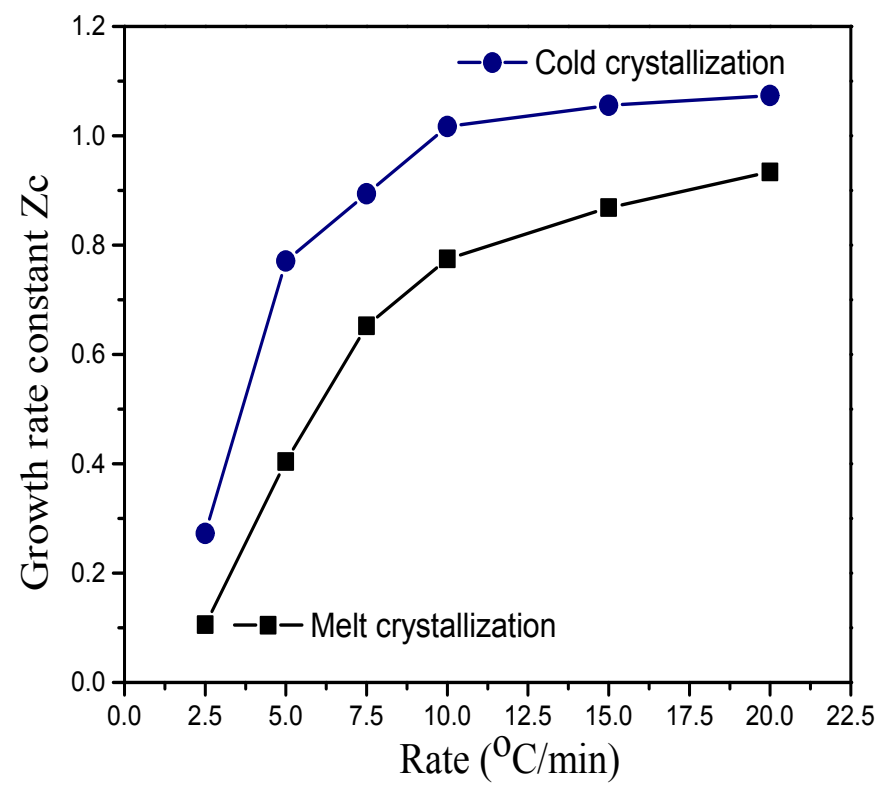

Figure S8. Comparison of the growth rate constant $\mathrm{Zt}$ values between the cold and melt nonisothermal crystallization of PPV. 

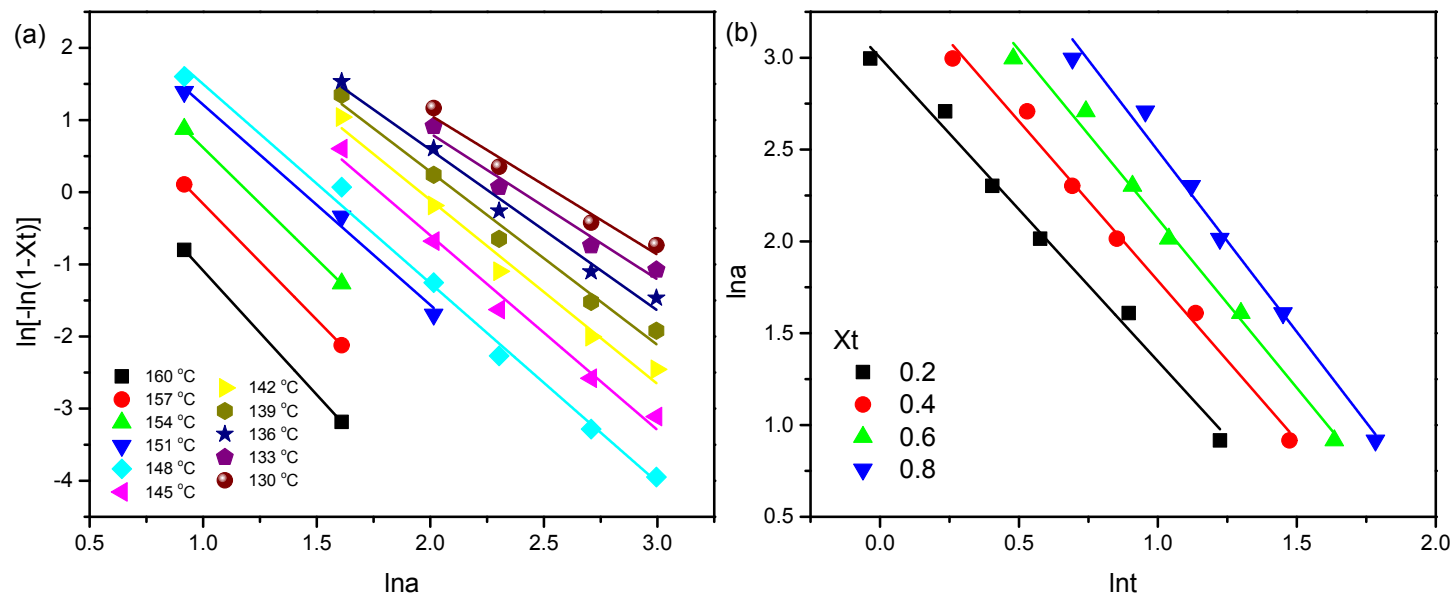

Figure S9. (a) Ozawa and (b) Mo plots for the non-isothermal melt crystallization of PPV.

Table S3. Ozawa parameters of the non-isothermal melt crystallization of PPV.

\begin{tabular}{|l|l|l|l|l|l|l|l|l|l|l|l|}
\hline $\begin{array}{l}\text { Temperature } \\
\left({ }^{\circ} \mathrm{C}\right)\end{array}$ & 160 & 157 & 154 & 151 & 148 & 145 & 142 & 139 & 136 & 133 & 130 \\
\hline $\mathrm{m}$ & 3.44 & 3.22 & 3.09 & 2.78 & 2.76 & 2.70 & 2.55 & 2.40 & 2.23 & 2.02 & 1.93 \\
\hline $\ln \mathrm{K}(\mathrm{T})$ & 2.35 & 3.06 & 3.71 & 3.99 & 4.26 & 4.80 & 4.99 & 5.09 & 5.04 & 4.86 & 4.93 \\
\hline $\mathrm{R}^{2}$ & - & - & - & $\begin{array}{l}0.98 \\
665\end{array}$ & $\begin{array}{l}0.99 \\
309\end{array}$ & $\begin{array}{l}0.98 \\
43\end{array}$ & $\begin{array}{l}0.98 \\
045\end{array}$ & $\begin{array}{l}0.98 \\
046\end{array}$ & $\begin{array}{l}0.98 \\
289\end{array}$ & $\begin{array}{l}0.95 \\
923\end{array}$ & $\begin{array}{l}0.95 \\
637\end{array}$ \\
\hline
\end{tabular}

Table S4. Results of the Mo analysis of the non-isothermal melt crystallization of PPV.

\begin{tabular}{|l|l|l|l|l|}
\hline $\begin{array}{l}\text { Relative } \\
\text { crystallinity X/\% }\end{array}$ & 20 & 40 & 60 & 80 \\
\hline $\mathrm{b}$ & 1.65 & 1.74 & 1.84 & 1.97 \\
\hline $\mathrm{F}(\mathrm{T})\left(\mathrm{K} \cdot \mathrm{min}^{\mathrm{b}-1}\right)$ & 3.00047 & 3.52314 & 3.96294 & 4.46655 \\
\hline $\mathrm{R}^{2}$ & 0.98834 & 0.98989 & 0.98991 & 0.98627 \\
\hline
\end{tabular}



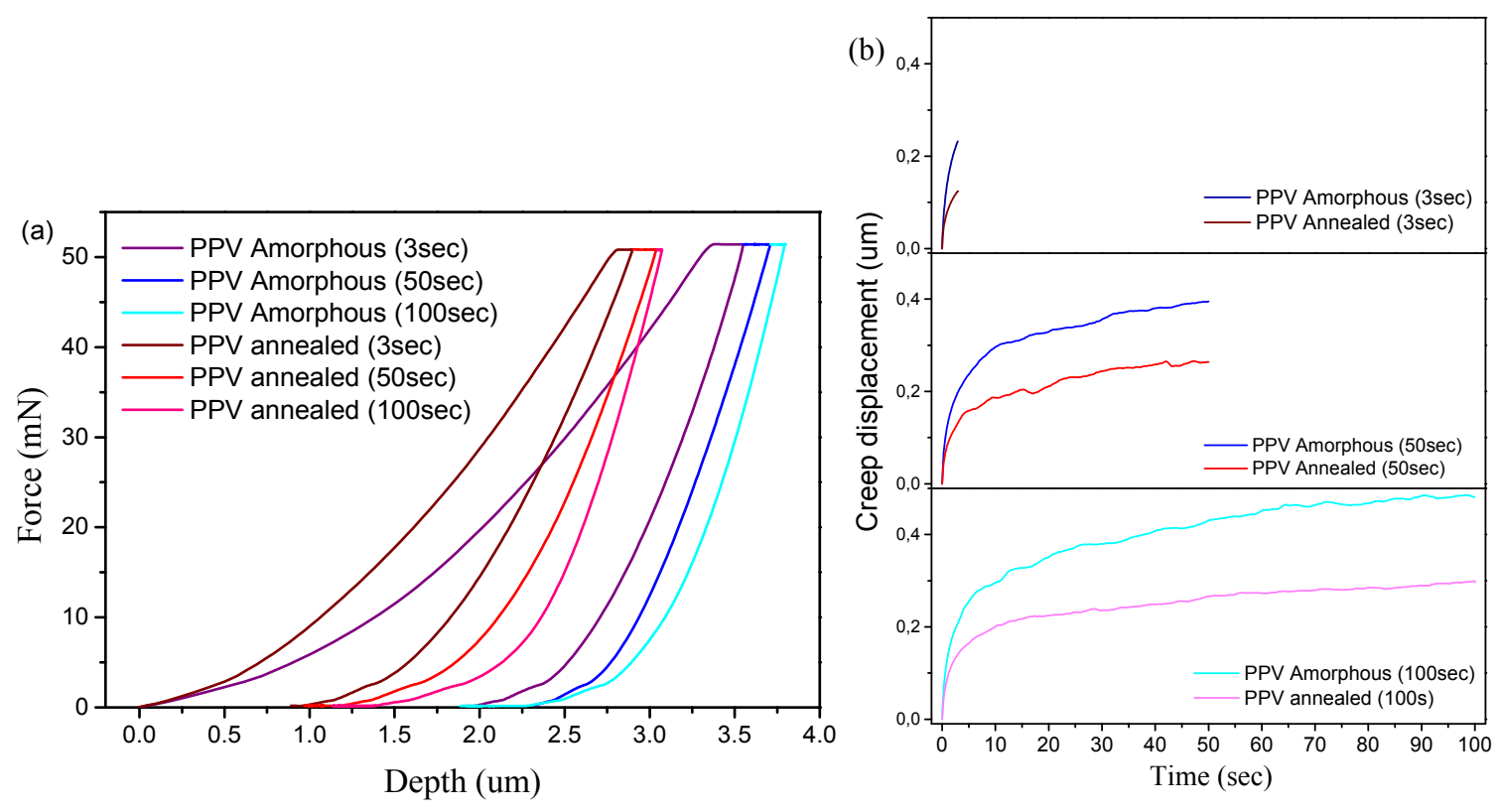

Figure S10. (a) Comparison of typical force-depth curves of Amorphous/Annealed PPV for different holding times and (b) creep displacement curves as a function of time. 